\title{
The COVID-19 Pandemic: A Health Crisis Managed or a Panic Response with Disastrous Future Consequences?
}

\author{
Yunus A. Luqmani ${ }^{a} \quad$ Ahmed El Hashim ${ }^{b}$ \\ ${ }^{a}$ Department of Pharmaceutical Chemistry, Faculty of Pharmacy, Kuwait University, Kuwait City, Kuwait; \\ ${ }^{b}$ Department of Pharmacology and Therapeutics, Faculty of Pharmacy, Kuwait University, Kuwait City, Kuwait
}

\section{Highlights of the Study}

- The COVID-19 pandemic has been misrepresented and mishandled, with detrimental future consequences for public health both through neglect of non-COVID-19 patients and enforced economic shutdowns, affecting livelihoods that are likely to be long lasting.

- In parallel, there has been an unprecedented outpouring of varying quality of scientific literature, as well as an information deluge in the international and social media, resulting in deterioration in public trust in both medical and political authorities, as well as the media.

- Mass vaccination is currently underway but at widely varying rates around the globe; its long-term effectiveness is uncertain but may create societal divisions as still many people remain unconvinced and resistant to this solution.

\section{Keywords}

COVID-19 pandemic · Social media - Disease mortality ·

Lockdown · COVID-19 vaccine

\begin{abstract}
In 1 year, COVID-19 spread rapidly worldwide affecting all societies and most age-groups. It has taken not only a toll of human lives (approaching 220 million people infected with 4.55 million reported deaths at time of writing) but also decimated every economy as countries struggle to control infection rates by introducing draconian lockdown and social distancing measures, bringing great suffering well beyond medical effects of the disease. A parallel pandemic has resulted in a deluge of information emanating from both scientific as well as international news media including social
\end{abstract}

karger@karger.com www.karger.com/mpp

Karger $\stackrel{\text { ' }}{5}$
C 2021 The Author(s).

Published by S. Karger AG, Basel

This is an Open Access article licensed under the Creative Commons Attribution-NonCommercial-4.0 International License (CC BY-NC) (http://www.karger.com/Services/OpenAccessLicense), applicable to the online version of the article only. Usage and distribution for commercial purposes requires written permission. media platforms. Fact and fiction, reality, and perception have become entangled; the only realistic solution, both medically as well as politically, is concerted global vaccination (which is currently underway) to reduce further infection by introducing universal immunity. However, public controversy rages due to widespread apprehension regarding necessity, immediate risks, and long-term safety of what is perceived as "fast-tracked" medication. While some concerns may be justified, much is due to misconception and misunderstanding. This review highlights some of the issues concerning the handling of the COVID-19 crisis by governments worldwide, the medical and scientific communities, and the media and how this may have laid the foundations for a far greater medical, social, and economic burden in the coming years. We present comparative data to challenge current conceptions of this disease in the more general con- 
text of human health to provide a perspective that seems to have been lost in the general panic. We need more rational approaches to the handling of a disease which is unlikely to disappear from our spectrum of afflictions even after the magnifying glass has been removed.

(c) 2021 The Author(s)

Published by S. Karger AG, Basel

\section{Introduction}

From the outset back in January 2020, the appearance of the coronavirus has been greeted with hesitancy and indecisive action on the part of both individual governments, acting out of concert, and prevarication and initial uncertainty from the World Health Organization (WHO) which usually seeks to assume a guiding leadership role at such times but seemed unable to do this effectively in this instance, perhaps straightjacketed by financial and political constraints. While persistently claiming to be "guided by science," which itself has in large measure been in some disarray, politicians around the world succumbed, sooner or later, to the more immediate forces of necessity and expediency in dealing with a crisis for which they appeared to be woefully unprepared, exhibiting mainly knee-jerk reactions to every new development $[1$, 2].

One might have expected that the previous outbreaks of severe acute respiratory syndrome, Middle-East respiratory syndrome, Ebola, and HIN1 flu should have been a wake-up call that resulted in the establishment of worldwide infrastructure and systems which enabled the adequate handling of such outbreaks at source. Unfortunately, the reality could not have been more different. The pandemic has been mishandled by both the worldwide political leadership and the global scientific community, with the "media" playing a significant role in aggravating and then compounding the problem $[1,3]$.

\section{A Global Panic Response to the Pandemic}

Early in 2020, the inability to effectively treat and cure infected individuals seriously affected by the coronavirus presented a significant challenge in dealing with not only its medical aspect but also in facing a logistical problem of dealing with a sudden surge of patients requiring immediate clinical treatment. For example, in the UK, the rallying cry for many months was "stay home, protect our NHS and save lives" [4], a sentiment echoed around the world. Governments responded by initially mount- ing hastily prepared campaigns to encourage hand washing, mask-wearing, and physical distancing and then ultimately enforced quarantine, which essentially entailed the partial, or at times complete, closure of the daily economy for weeks or months. The consequences of this have been variable but quite significant and have underscored not only the interdependence of the global community but have also exposed the surprising fragility of some of our societies. In richer countries, it has manifested largely in a selective reduction in economic prosperity and loss of jobs leading to relative hardship, with a small proportion being reduced to dependence on food-handouts. But for countries where much of the population lives near or below the poverty line, jobs and hence income deprivation have had very serious consequences. Mass worker migrations out of cities (due to job losses) back to their rural areas were seen in parts of India. Such measures, in areas of conflict, have also greatly exacerbated an already dire situation $[5,6]$. The full longterm effects of this will become apparent only in the coming years.

The other serious side effect of this pandemic is the forced postponement (due to lack of, and reassignment, of healthcare resources) of ongoing treatment for patients suffering from other illnesses, albeit some regarded as less urgent. This is expected to lead to future excess deaths [7]. So, have these lockdown measures really been successful in achieving disease control in the way they have been implemented [8]? Or will this prove to have been a self-destructive policy, with the combination of these 2 factors resulting, further down the line, in the payment of a far greater price for achieving a "pyrrhic victory" against this tiniest of adversaries? Already, variations are clearly apparent between different countries, with further lockdown measures being reintroduced across Europe, whereas in many Asian countries including China, and in smaller nations such as Kuwait and the United Arab Emirates, life has returned to "near normal" since some months, albeit with intermittently imposed partial restrictions. Undoubtedly, social behavior in adherence to simple non-medical preventive measures has been a determining factor, as well as strict enforcement measures for quarantine of COVID-19 PCR-positive individuals for the prescribed 10-14-day period to restrict transmission. "Track and trace" techniques appear to have been intermittently successful in some countries (e.g., Singapore) but not widely adopted; another failure of international cooperation? 


\section{The Evolution of the Clinical Response to the Pandemic}

In a year of tumult, science and politics have made uncomfortable bedfellows with decisions swinging back and forth by both parties unable to cope with a rapidly evolving landscape [9]. The immediate medical response to the viral infection was understandably focused on stabilizing moderate-to-severely-ill patients long enough for recovery and for their immune system to combat the virus. This primarily focused on respiratory ventilation as the lungs appeared to be the main target of the infection and most of the symptoms were associated with breathing impairment [10]. However, the lack of sufficient intensive care unit facilities and inadequate availability of protective clothing for caregivers in face of initial uncertainty regarding the mode of viral transmission made things worse, and has been a worldwide problem [11, 12].

Indeed, it took several months to address these issues and was the foremost driving factor in government decisions on how to handle a situation that we were told threatened to overwhelm the medical resources of even the richest countries $[13,14]$. To what degree this was really a danger, and whether the measures taken prevented it, remains to be determined.

\section{Potential Treatments}

Simultaneously, there was a scramble in the scientific community to find existing drugs to re-purpose either as anti-viral or anti-inflammatory agents in order to alleviate mostly the respiratory symptoms of the infection. This resulted in a number of candidates. Unfortunately, however, the public received confusing and conflicting messages from not only influential political leaders but also from respected figures of the major public health organizations. Indeed, some politicians even promoted dangerous crackpot ideas such as the ingestion of disinfectants or high alcohol content beverages such as vodka, or exposure of the mouth or skin to ultraviolet light.

Moreover, some of the earliest studies performed at the start of 2020 had indicated that the anti-malarial drug hydroxychloroquine had beneficial effects on their patients, possibly due to its anti-inflammatory properties. Consequently, this received an Emergency Use Authorization (EUA) from the FDA on 28 March 2020. However, this was revoked very soon after on 15 June, mainly due to reports of cardiac and other toxicities and uncertain efficacy in subsequent studies [15]. Further confusion arose after results published in the prestigious medical journal Lancet not supporting the use of hydroxychloroquine were then retracted due to lack of verification of the original data [16]. Consequently, this drug has been removed from mainstream COVID-19 treatment protocols. Another treatment, involving convalescent plasma was also put forward as a possible solution and received FDA EUA approval in late August. However, its benefits were somewhat over-stated by the FDA, possibly under political pressure as they later acknowledged a possibly premature decision and have recently limited its use $[17$, 18].

These examples are mentioned to highlight the fact that many clinical decisions were taken by respected bodies in haste, then having to backtrack; this created enormous confusion within the medical fraternity, which then filtered through to the general public, leading to a considerable loss of trust [19]. This has also prompted many people to turn to "alternative medicine" as potential therapies [20,21]. So, inevitably, there has been a plethora of herbal and natural remedies unsupported by any clinically proven medical benefit, exploiting in large part the desperation of gullible and vulnerable persons, often for economic gain or even just for publicity; admittedly, some of these may be with good intentions.

Among the first anti-viral treatments proposed was the drug remdesivir which was previously only an investigational drug for hepatitis/Ebola [22]. It was found to shorten recovery periods in patients with severe disease, decrease mortality rate, and stabilize disease. This received a limited EUA from the FDA in May 2020 which has been broadened since October 2020. As COVID-19 is typically characterized by inflammation, particularly airway inflammation, the commonly used steroid dexamethasone proved to be one of the most effective recourses for patients with severe disease requiring supplemental oxygen therapy, preventing further damage to the lungs and allowing the body to mount its own effective immune response [23]. A strategy recently announced by Regeneron Pharmaceuticals is the use of a cocktail of neutralizing monoclonal antibodies casirivimab and imdevimab (REGEN-COV) [24], which are claimed to be effective against both the originally identified virus as well as some emerging variants that have arisen as a result of ongoing mutations in the coronavirus genome.

These treatments from Regeneron and also Eli Lilly (bamlanivimab) have both been approved by the FDA for emergency use in patients with moderate-to-severe COVID-19 within the first few days of infection to prevent more severe illness $[25,26]$. During the early part of 2021, 
there has been interest in the anti-parasitic drug ivermectin [27], which is approved for veterinary use and is being promoted by medical groups particularly in South Africa, but so far, the FDA maintains that they have not received sufficient evidence to justify approval for use against COVID-19 and so remain non-committal either way [28].

\section{The Parallel COVID-19 Scientific Information Pandemic}

It is not uncommon for scientists to suddenly shift focus intensely, and usually briefly, to an important new development, but the response to COVID-19 has few comparisons if any in the medical literature. The WHO declared COVID-19 a "pandemic" on 11 March 2020, after it had spread across most parts of the world. Meantime, a parallel pandemic had already begun. Since January 2020 , there has been a sudden deluge of scientific articles on COVID-19. The digital information platform "Dimensions" (www.dimensions.ai) has recorded more than 308,923 publications, 28,841 research grants, $6,425,123$ patents, and 19,778 clinical trials fed into more than 71,943 official policy documents (numbers at the time of writing this review).

Despite the very genuine intentions of the scientific community to get a clear understanding of this disease and how to control and treat it, crucial medical efforts have been drowned in an "unholy scramble" by a significant minority of researchers of every ilk jumping on the publishing bandwagon. Even before COVID-19, the world of scientific medical research publishing had already become increasingly adulterated with low-quality and often highly questionable papers, subject to less careful scrutiny and genuine peer review by subject experts. These are often to be found in so-called predatory journals that have appeared in recent years in significant numbers, more as business enterprises than repositories of scientific knowledge and where anything, irrespective of standard or quality, can be published, with little or no scrutiny of scientific rigor or contribution [29]. Lamentably, in the wake of this enormous COVID-19 surge, there may have been a further "relaxing" of publishing norms and controls even among some of the reputed benchmark journals [30]. This has created a trust issue with the scientific community. Ironically, it is now more imperative than ever before to enforce the usually strict publishing controls and conduct due diligence before allowing scientific articles into the public domain. This will ensure that only genuine authentic research studies of first-hand ex- perience of management of large numbers of COVID-19 patients (not just individual case studies), or properly conducted clinical trial studies, which have been peer reviewed, are published, so good clinical/medical information is not submerged in a flood of unreliable, possibly dangerously misleading and even completely fake data.

Scientific journals/publishers may have also inadvertently contributed to this problem. For example, some online journal systems allow initial pre-exposure of work which has not yet undergone a rigorous peer-review process into the public domain, for feedback critique intended to help improve submissions for subsequent formal publication. This was never intended as established information but simply for other investigators to gain early access to work that could be helpful in their own research. However, this has led to the release of a significant amount of information which may not eventually reach the required scientific standards of publication after the "peerreview process"; COVID-19 has brought this matter to the forefront.

Recognizing the importance of disseminating only reliable and trustworthy information, two publicly available resources, the Novel Coronavirus Research Compendium (NCRC) and the COVID-19 Open Research Dataset (CORD-19), have been created by an army of data scientists, software developers, journal publishers, and staff from the John Hopkins School of Public health, backed by large technology firms and the US Administration $[31,32]$. These resources constitute a databank of thousands of freely available papers. The rationale behind these projects was to facilitate the development of textmining and information retrieval systems from highly resourced data and structured original, high-quality research papers on COVID-19 and related historical coronavirus research with the objective of providing accurate, relevant information for global public health action by clinicians, public health practitioners, and policy makers $[33,34]$.

\section{Information Deluge from the Media}

In addition to the dissemination of scientifically based data (with the reservations mentioned earlier), there has been a seemingly endless outpouring of information from both mainstream international media outlets as well as fringe and politically slanted news stations. On the one hand, in many countries, state-controlled media promote the official line, while in other countries with ostensibly "free media" may choose to disseminate governmental 
Table 1. Incidence and mortality for COVID-19 in specified geographic locations

\begin{tabular}{lllll}
\hline Region & $\begin{array}{l}\text { Observed PCR } \\
\text { +ve cases* }\end{array}$ & $\begin{array}{l}\text { Recorded number } \\
\text { of deaths** }\end{array}$ & $\begin{array}{l}\text { Case fatality } \\
\text { (deaths as \% of +ve cases) }\end{array}$ & $\begin{array}{l}\text { Total } \\
\text { population }\end{array}$ \\
\hline Worldwide & $116 \mathrm{~m}$ & $2.6 \mathrm{~m}$ & 2.24 & $7.8 \mathrm{bn}$ \\
total population
\end{tabular}

* The PCR method was used to determine the presence of the coronavirus in the swab sample of nasal secretion or saliva. ** Death recorded as due to COVID-19 on the death certificate. All numbers have been rounded. Source: WHO website [36].

guidelines and/or have their own agenda too. Indeed, cynics may say that they make the news particularly by selection of what they choose to broadcast and how they slant the information often in subtle nuances. Whatever the case, the insatiable public demand to provide the "latest data" in hourly news bulletins has no doubt led reporters, with none or very limited scientific training or even understanding, to hurriedly translate scientific information (sometimes irrespective of its source or quality or merit), into sensationalized "breaking news." Indeed, the scientific, and particularly the medical, community has itself been placed under microscopic observation. Often scientists and clinicians, under intense pressure to feed this craving, inadvertently or otherwise contribute to this. Now, further add to this the literally millions of information bites flowing seamlessly through the electronic social media platforms that hallmarks the present era, and it should be hardly surprising that, in a situation where literally everyone has an apparent vested interest, confusion reigns supreme, and opinions sway with every internet posting or tweet. While these means of communication between people have undoubtedly had benefits in numerous ways, it is a double-edged sword, educating and informing but also providing opportunity for great misinformation, manipulation, and plain mischief, for example, in propagation of conspiracy theories [35]. Numerous studies have been carried out to examine the influence of news media reporting on public perceptions and behavior which highlight a rather complex relationship [3638]. An interesting aspect is the explosion in media technologies catering for the new "stay-at-home" and "workfrom-home" lifestyle imposed through lockdown [39]. This has accentuated the influence of family and broader social groups on individual perceptions and opinions.

The Response to the COVID-19

Pandemic

\section{The Global Impact of COVID-19 in Perspective: Perception versus Reality}

It is pertinent to present here some perspective on this disease in the context of human mortality in general. There are a number of different sources of information for statistics on COVID-19 and for population demographics including mortality from diseases. For self-evident reasons, there are substantial variations in these in terms of accuracy and reliability and will therefore be used here with that acknowledgment and only as a general guide to illustrate the point.

The presence of the coronavirus in infected individuals is established using a PCR test. The data in Table 1 [40] show the incidence and mortality of COVID-19 globally and in the countries with the highest case mortalities (at the time of writing of this article). The case mortality rates as a percentage of recorded cases in these countries vary from 1.41 to $2.95 \%$ (excluding the figure for Kuwait in the Table, given as a local comparison and which incidentally has fared very well compared to many other countries), with the worldwide average being $2.24 \%$. When expressed as a percentage of the total population, the mortality rates vary in the groups analyzed here from 0.01 to $0.18 \%$. In other words, COVID-19 has (to date) not in any way directly medically affected $97.05 \%$ of the world population and not killed $99.82 \%$ of the world population. Moreover, it is generally accepted that the recorded number of COVID-19-positive individuals is likely to represent a gross underestimate of the actual number of people who have been infected by the coronavirus. Random testing of non-symptomatic individuals or those with symptoms too mild to warrant hospital attention has most likely been very limited and only performed in very few coun- 
tries for logistic and economic reasons. Some medical experts believe that the real (incidence) figure including undetected infections could be as much as 5-10 times higher [41]. Thus, the real case fatality ratio is likely to be even smaller than the numbers indicated in Table 1, but this will be impossible to determine with any accuracy [42]. Perhaps, mathematical modeling predictions may provide some guesstimates. Of course, to what extent the safety measures of social distancing, mask-wearing, and lockdown have reduced potentially higher infection and fatality numbers will remain a matter for conjecture. Another parameter which could be illuminating but not readily available from the published datasets is the number of people who were tested but were negative as the most important consideration is not how many people become infected with the virus but how many succumb to it and need medical attention. This may be a better indicator of the seriousness of the infection.

Mortality figures are therefore likely to be a more reliable and informative parameter, though still subject to some distortions due to two main reasons. First, there are very likely to be variations in recording the cause of death as due to COVID-19 or another associated illness. This point has been extensively debated and the subject of much dispute. The WHO guidance is that "a death due to COVID-19 is defined for surveillance purposes as a death resulting from a clinically compatible illness, in a probable or confirmed COVID-19 case, unless there is clear alternative cause of death that cannot be related to COVID disease." The other perhaps more numerically significant factor is inaccurate or lack of recording in poorer countries with less well-developed healthcare systems, particularly in their rural areas.

What is also very interesting is that arguably, medicare systems, social structure, and economics in the USA and the UK might reasonably be expected to give them significant advantage over India and Brazil, and yet, the overall mortality rates in the USA and the UK are 5-6-fold higher than the world average, 16-18-fold higher than in India, and approximately 30\% higher than in Brazil. To fathom the reasons for these differences will no doubt entail analysis of many confounding factors for epidemiologists to ponder over; for example, climatic differences, social structure, and age of population [43]. However, in the current context, one might conclude that the absence of effective medical intervention has not really made a significant impact in terms of the overall numbers.

Accurate data on hospitalizations are very difficult to obtain except in the few countries where records are reliable. We were unable to find any database of aggregated numbers, but as an example, in the USA, the COVID Tracking Project [44] and Our World in Data [45] compile data on numbers of hospital admissions at a given time. Their data show peaks of admissions during late March $(60,000)$, July $(60,000)$, and in late January 2021 $(120,000)$. The respective figures for patients in intensive care units are about 15,000,10,000, and 23,000. As an academic exercise, let us aggregate these numbers and assume that nothing was done, and all of these people had unfortunately died; and then, double that number; that number comes to 96,000 . Add this to the mortality number in Table 1 and we get about 623,000, which will increase the percentage mortality for COVID-19-positive patients from 1.82 to 2.15 or from 0.16 to $0.19 \%$ of the total population of the USA. Even in this extreme hypothetical situation, which may well be close to reality in some poorer countries, the proportion remains relatively very small. It will of course be quite reasonably argued that these numbers, no matter how extremely low the percentage is, are still considerable in absolute terms and any number of human lives are worth saving if it is possible.

So, let us then compare the number of deaths due to COVID-19 with those from other causes during a similar period. As such data usually lag, we have used WHO data of 2019 and compared it with those of 2020 for COVID-19, which are readily available. Table 2 shows mortality numbers from the top 10 leading causes of death worldwide due to disease. Not included in the above, HIV/AIDS claimed about 690,000 lives in 2019, but the majority of affected individuals (estimated at $38 \mathrm{~m}$ worldwide) are located in sub-Saharan Africa and mostly out of the interest of the mainstream Western media [46, 47]; that is, not receiving too much public attention.

Another major cause of death not included in Table 2 is hunger, which is closely linked to poverty. As early as April 2020, a paper from the United Nation University World Institute for Development Economics Research warned that the economic fallout from COVID-19 could increase world poverty by half a billion people (around $6.5 \%$ of the global population), the first time it has increased globally in 30 years, since 1990. It forecast that 135 million people, or nearly $2 \%$ more of the world's population than currently, could become destitute as a consequence of COVID-19 [48, 49]. This is despite the fact that the solution to hunger has actually been known for a long time and is readily available and proven to be $100 \%$ effective; it is called food! Periodically, this "disease" attracts popular public attention, the most spectacular example being the "Band aid" campaign to highlight famine in Ethiopia in 1984. But, for the most part, it rarely makes 
Table 2. Leading causes of death from disease globally in 2019

\begin{tabular}{lll}
\hline & Disease & $\begin{array}{l}\text { Number of } \\
\text { deaths (millions) }\end{array}$ \\
\hline 1 & Ischemic heart disease & 8.88 \\
2 & Alzheimer's disease and other dementias & 1.63 \\
3 & Stroke & 6.19 \\
4 & Trachea, bronchus, and lung cancers & 1.78 \\
5 & Chronic obstructive pulmonary disease & 3.22 \\
6 & Lower respiratory infections & 2.59 \\
7 & Colon and rectum cancers & 0.92 \\
8 & Kidney diseases & 1.33 \\
9 & Hypertensive heart disease & 1.14 \\
10 & Diabetes mellitus & 1.49 \\
11 & COVID-19* & 1.75 \\
\hline
\end{tabular}
2020.

Extracted from the WHO website [36]. * January-December

the international news except in conjunction with reports on conflagrations in Africa, Yemen, Syria, or the like. These comparisons are not in any way meant to belittle the many who have lost their lives or to diminish the impact of COVID-19 but to put it into more rational overall perspective, in view of the manner in which it is being presented - that of a major crisis for humanity.

\section{A Response to Disease Like No Other in History}

No other disease in recorded history has ever elicited anything approaching the kind of global response seen with COVID-19, although both individually, and certainly collectively, other diseases claim far more lives, and on an ongoing basis, continuing year after year. Considering these realities, one might be justified in saying that the response to COVID-19 has been extreme, akin to using a sledgehammer to knock a small nail into a wall to hang a picture. The collateral damage may far exceed the benefit that is perceptibly achieved. If it were simply a matter of paying greater attention to the treatment of COVID-19 that might be justified on the basis that it is caused by a new, easily communicable virus that can spread rapidly unchecked and incur further fatalities. But, the issue is the manner in which "control" has been approached. Economic shutdown, on an unprecedented scale, has been a reflex panic-stricken solution to a disease that is actually much less dangerous to humanity than the many we live with each day and indeed will continue to do so long after COVID-19 has gone. So how did we get to this?

The Response to the COVID-19

Pandemic
For more than a year, we have been relentlessly bombarded daily, indeed hourly, with every tiny event regarding infection from COVID-19. It has been discussed ad nauseum from every conceivable angle and every viewpoint by every expert in the field available for comment. It has dominated every news outlet, with emotional stories and scenes of mass graves becoming imprinted into our psyche. Many websites, at the click of a button, inform us second by second of the death toll in every country of the world with complete statistical breakdown and analysis, graphs, tables, and figures. We have been convinced (dare we say indoctrinated) that in COVID-19, we are faced with the greatest threat to the existence of humanity, and all actions are justified. How many times during 2020 have we been informed of the number of deaths from stroke or kidney failure or neonatal death or traffic accidents, although the numbers are comparable or greater? We have reached the stage where we are aghast at hearing that someone we love has died from COVID-19 and somehow a life lost to COVID-19 has become more tragic than a life lost to heart failure, cancer, diarrhea, influenza, or AIDS. There is indeed a chasm here between the perception of the "deadliness" of this disease and the mathematical reality of it.

\section{Reasons for Vaccine Hesitancy and the Likely Outcome}

For better or for worse, we have reached the stage where it has been determined by political and medical authorities in many parts of the world that restoration of complete social normality is strictly contingent upon the widespread reduction of COVID-19 infections. In the absence of any really effective treatment, this can only be achieved through immunization. Proposals to allow this to happen through acquisition of natural and passive "herd immunity" has met with widespread criticism from all quarters as it is considered that this would lead to an unacceptable number of deaths in the process as well as disproportionately affecting poorer sections of society [50-52]. The other way to achieve immunity is by active vaccination and is the preferred strategy. To this end, there has been a massive global effort to produce suitable vaccines. A number of these have been authorized by various national and international bodies and since mid-December 2020 are being administered to large segments of the population of many countries. It is thought that to achieve an acceptable level of population (herd) immunity, at least $60-70 \%$ of the population or more needs to

Med Princ Pract 2022;31:1-10

DOI: $10.1159 / 000520258$ 
be vaccinated [53]. However, despite large-scale production capacity, logistical and political issues have hampered equitable access to some of the vaccines, such that most of the supplies have gone preferentially to the G20 nations. The WHO has stressed that the problem will not be resolved unless all countries are able to vaccinate their populations, and therefore, the rich must help the poor. There is also another almost paradoxical situation. On the one hand, there is a frenzied demand for immediate and urgent universal vaccination spurred on by governments and by the WHO, most medical authorities, and the news media, and on the other, a wavering suspicion and hesitancy among the public (and even within some in the medical fraternity) in taking the new vaccines, fueled by counterarguments from a number of both legitimate as well as conspiratorial sources.

Although vaccines have been around for decades and have contributed very significantly to the practical eradication of several debilitating infectious diseases and relegation of many others to the minor division of global killers, their long-term safety and efficacy have generally been well tested before universal acceptance. The speed and innovative design of the two most widely administered vaccines from BioNTech and Moderna, as well as others, have raised concerns over possible side effects and longer term safety. Again, this is, for the most part, due to the failure to understand the biological intricacies of these medications and the somewhat confusing tag of "genetic" vaccines, suggesting that they may integrate with the human genome. For now, however, this has not prevented the vaccination of substantial numbers of individuals in the UK, the USA, Israel, United Arab Emirates, Chile, China [54], and other countries who have had preferential access to substantial quantities of vaccines. Added to this are now further complications arising from the emergence of more penetrative mutant forms of the virus, casting uncertainties as to whether antibodies elicited by immunization with either the mRNA/protein of the original viral strain or vaccines using more traditional adenoviral constructs or attenuated virus, will be active against these new forms and indeed against additional mutants which will quite likely appear. Also, more and more the scientific opinion is suggesting that the vaccinated immunity may be shorter lived than initially thought, requiring booster injections. In the UK, and some other countries, these are already underway. Perhaps, further modified vaccines may also be needed, with the accompanying economic and logistical implications. The old adage of more speed and less haste appears to have been largely discarded in favor of a "fast-and-furious" pragmatic fix. Consid- ered scientific procedure and careful analysis of reliable data have been subordinated to the demands of the immediate political agenda. Questions such as do the overwhelmingly vast majority of infected individuals who remain asymptomatic or only mildly symptomatic really need vaccination have been swept aside. It also seems, presumably for logistical reasons, that vaccinated individuals are not being routinely tested for the presence of anti-coronavirus antibodies to determine its success, and so, authorities are simply relying on the indirect observations of a slowdown in infection rates. Therefore, the success of vaccination may be rather more complicated to determine as other confounding (and opposing) factors such as increasing natural immunity on the one hand and increasing complacency with regard to mask-wearing and physical distancing will need to be considered.

Another controversial issue is that while the taking of a vaccine is not currently compulsory, there is much discussion in certain countries regarding the issuance of some form of a "vaccine passport," allowing preferential access to certain activities that will be denied to individuals who have not been vaccinated. Indeed, in Kuwait, only vaccinated individuals (proven by a certification obtained through registration on an "Immune" app) are allowed into venues such as malls, restaurants, cinemas, and other public places with large numbers of people [55]. This is also becoming more commonly practiced at large public venues in the UK, where since July 2021 (qualifying), vaccinated individuals are exempted from the 10-day quarantine previously imposed on all visitors arriving in the country. While such measures may prompt many, especially those who are mildly reluctant, into getting vaccinated, it will undoubtedly initiate a divisive and potentially dangerous precedent and further politicization of matters related to human health. Legal compulsion in the taking of any kind of medication could be a very slippery slope.

\section{Conclusion}

When the dust has finally settled, hopefully early in 2022, there will be opportunity to take stock of how this viral infection has been handled. Many questions will need to be answered. Did the governments of the world, and the health authorities in whom we put our public trust, by their actions, limit a crisis for humanity? Or did they create unnecessary and deadly panic and resort to unnecessary draconian measures, leaving us with a legacy that will exact a far greater toll of human lives both from 
the substantial economic ruin and from neglect of all things not COVID-19? While we are hopefully at the albeit longish tail end of this particular pandemic, return to life as it was pre-COVID-19 is likely to depend on mass vaccination, through one type of persuasion or another. While outbreaks of reinfection among vaccinated individuals are giving rise to increased concerns that immunity may be of variable duration, the current solution is through the use of "booster" injections. However, identifying people needing such intervention will be a complex issue, with the various antibody tests measuring different biological responses [56].

Like many other diseases, a lack of effective treatment means that we rely crucially upon acquired immunity. To achieve this will need more responsible cooperation between governments, the medical fraternity, and the mainstream as well as social media to present a more coherent and unified message as opposed to the confused and frequently contradictory information and advice that is impeding return to normality. Meanwhile, the economic malaise, ranging from compulsory PCR tests for travel and quarantine to destroyed businesses and livelihoods, is continuing to plague the overwhelming majority of humanity which has been unaffected medically by $\mathrm{CO}$ VID-19.

\section{Conflict of Interest Statement}

The authors have no conflicts of interest to declare.

\section{Funding Sources}

There was no funding for this manuscript.

\section{Author Contributions}

Both authors contributed to the intellectual content of this review and the writing of it.

\section{References}

1 Escandón K, Rasmussen AL, Bogoch II, Murray EJ, Escandón K, Popescu SV, et al. COVID-19 false dichotomies and a comprehensive review of the evidence regarding public health, COVID-19 symptomatology, SARSCoV-2 transmission, mask wearing, and reinfection. BMC Infect Dis. 2021;21(1):710.

2 Fishel SR, Fletcher A, Krishna S, McKnight U, du Plessis G, Shomura C, et al. Politics in the time of COVID. Contemp Political Theory. 2021;20:657-89.

3 Wicke P, Bolognesi MM. Framing COVID-19: How we conceptualize and discuss the pandemic on Twitter. PLoS One. 2020; 15(9):e0240010.

4 Hope C, Dixon H. The story behind "stay home, protect the NHS, save lives": the slogan that was "too successful". 2020. Available from: https: //www.telegraph.co.uk/politics/2020/05/01/story-behind-stay-homeprotect-nhs-save-lives/.

5 World Bank. Global economic prospects. Washington, DC: World Bank Publications; 2021. Available from: https://www.worldbank.org/en/publication/global-economicprospects.

6 World Bank. The global economic outlook during the COVID-19 pandemic: a changed world. 2020. Available from: https://www. worldbank.org/en/news/feature/2020/06/08/ the-global-economic-outlook-during-thecovid-19-pandemic-a-changed-world.

7 Zeymer U, Gitt A, Thiele H. [COVID-19 pandemic: effects on clinical care of cardiovascular patients in spring 2020]. Herz. 2021;46(2): $115-9$.
8 Ghosal S, Bhattacharyya R, Majumder M. Impact of complete lockdown on total infection and death rates: a hierarchical cluster analysis. Diabetes Metab Syndr. 2020;14(4):707-11.

9 Horton R. Offline: science and politics in the era of COVID-19. Lancet. 2020;396(10259): 1319.

10 Amirfarzan H, Cereda M, Gaulton TG, Leissner KB, Cortegiani A, Schumann R, et al. Use of helmet CPAP in COVID-19-A practical review. Pulmonology. 2021;27(5):413-22.

11 Karim N, Afroj S, Lloyd K, Oaten LC, Andreeva DV, Carr C, et al. Sustainable personal protective clothing for healthcare applications: a review. ACS Nano. 2020;14(10): 12313-40.

12 Phua J, Weng L, Ling L, Egi M, Lim CM, Divatia JV, et al. Intensive care management of coronavirus disease 2019 (COVID-19): challenges and recommendations. Lancet Respir Med. 2020;8(5):506-17.

13 Martin-Delgado J, Viteri E, Mula A, Serpa P, Pacheco G, Prada D, et al. Availability of personal protective equipment and diagnostic and treatment facilities for healthcare workers involved in COVID-19 care: a cross-sectional study in Brazil, Colombia, and Ecuador. PLoS One. 2020;15(11):e0242185.

14 Tyrrell CSB, Mytton OT, Gentry SV, Thomas-Meyer M, Allen JLY, Narula AA, et al. Managing intensive care admissions when there are not enough beds during the COVID-19 pandemic: a systematic review. Thorax. 2021;76(3):302-12.
15 US FDA. FDA cautions against use of hydroxychloroquine or chloroquine for COVID-19 outside of the hospital setting or a clinical trial due to risk of heart rhythm problems. 2020. Available from: https://www.fda. gov/drugs/drug-safety-and-availability/fdacautions-against-use-hydroxychloroquineor-chloroquine-covid-19-outside-hospitalsetting-or.

16 Mehra MR, Desai SS, Ruschitzka F, Patel AN RETRACTED: hydroxychloroquine or chloroquine with or without a macrolide for treatment of COVID-19-a multinational registry analysis. Lancet. 2020. Epub ahead of print.

17 Marcus AD. FDA limits use of convalescent plasma as Covid-19 treatment. 2021. Available from: https://www.wsj.com/articles/fdalimits-use-of-convalescent-plasma-as-covid19-treatment-11612537239.

18 Perrone M, Riechmann D. FDA chief apologizes for overstating plasma effect on virus. 2020. Available from: https://apnews.com/article/a7f0e8aac34a860ad502912564681b7c.

19 Enria L, Waterlow N, Rogers NT, Brindle H, Lal S, Eggo RM, et al. Trust and transparency in times of crisis: results from an online survey during the first wave (April 2020) of the COVID-19 epidemic in the UK. PLoS One. 2021;16(2):e0239247.

20 Ang L, Song E, Lee HW, Lee MS. Herbal medicine for the treatment of coronavirus disease 2019 (COVID-19): a systematic review and meta-analysis of randomized controlled trials. J Clin Med. 2020;9(5):1583. 
21 Mirzaie A, Halaji M, Dehkordi FS, Ranjbar R, Noorbazargan $\mathrm{H}$. A narrative literature review on traditional medicine options for treatment of corona virus disease 2019 (COVID-19). Complement Ther Clin Pract. 2020; 40:101214.

22 Liang C, Tian L, Liu Y, Hui N, Qiao G, Li H, et al. A promising antiviral candidate drug for the COVID-19 pandemic: a mini-review of remdesivir. Eur J Med Chem. 2020;201: 112527.

$23 \mathrm{WHO}$. WHO welcomes preliminary results about dexamethasone use in treating critically ill COVID-19 patients. 2020. Available from:

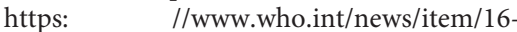
06-2020-who-welcomes-preliminary-resultsabout-dexamethasone-use-in-treating-critically-ill-covid-19-patients.

24 Weinreich DM, Sivapalasingam S, Norton T, Ali S, Gao H, Bhore R, et al. REGN-COV2, a neutralizing antibody cocktail, in outpatients with COVID-19. N Engl J Med. 2021;384(3): 238-51.

25 FDA. Coronavirus (COVID-19) update: FDA authorizes monoclonal antibody for treatment of COVID-19. 2020. Available from: https: //www.fda.gov/news-events/press-announcements/coronavirus-covid-19-updatefda-authorizes-monoclonal-antibody-treatment-covid-19.

26 FDA. Coronavirus (COVID-19) update: FDA authorizes monoclonal antibodies for treatment of COVID-19. 2020. Available from: https: //www.fda.gov/news-events/press-announcements/coronavirus-covid-19-updatefda-authorizes-monoclonal-antibodies-treatment-covid-19.

27 Ramirez C, Herrera-Paz EF, Peralta G, Rodriguez $\mathrm{G}$, Duron RM. Is ivermectin ready to be part of a public health policy for COVID-19 prophylaxis? EClinicalMedicine. 2021;32: 100744.

28 Wehbe Z, Wehbe M, Iratni R, Pintus G, Zaraket $\mathrm{H}$, Yassine HM, et al. Repurposing ivermectin for COVID-19: molecular aspects and therapeutic possibilities. Front Immunol. 2021;12(1040):663586.

29 Taylor GA. Predatory journals: a different pandemic. Pediatr Radiol. 2021;51(4):516-8.

30 Mehra MR, Ruschitzka F, Patel AN. Retraction: hydroxychloroquine or chloroquine with or without a macrolide for treatment of COVID-19-a multinational registry analysis. Lancet. 2020;395(10240):1820.

31 Allen Institute for AI. COVID-19 Open Research Dataset Challenge (CORD-19). Available from: https://www.kaggle.com/allen-institute-for-ai/CORD-19-research-challenge.
32 Johns Hopkins Bloomberg School of Public Health. 2019 Novel Coronavirus Research Compendium (NCRC). Available from: https://ncrc.jhsph.edu/.

33 Johns Hopkins Bloomberg School of Public Health. What we do. Available from: https:// ncrc.jhsph.edu/what-we-do/.

34 Wang LL, Lo K, Chandrasekhar Y, Reas R, Yang J, Eide D, et al. Cord-19: the covid-19 open research dataset. ArXiv [Preprint]. 2020.

35 Bolsen T, Palm R, Kingsland JT. Framing the origins of COVID-19. Sci Commun. 2020; 42(5):562-85

36 Ophir Y, Walter D, Arnon D, Lokmanoglu A, Tizzoni M, Carota J, et al. The framing of COVID-19 in Italian media and its relationship with community mobility: a mixed-method approach. J Health Commun. 2021;26(3): 161-73

37 Ophir Y, Jamieson KH. The effects of media narratives about failures and discoveries in science on beliefs about and support for science. Public Underst Sci. 2021. Epub ahead of print.

38 Ophir Y. Coverage of epidemics in American newspapers through the lens of the crisis and emergency risk communication framework. Health Secur. 2018;16(3):147-57.

39 Nguyen D. Mediatisation and datafication in the global COVID-19 pandemic: on the urgency of data literacy. Media International Australia. 2021;178(1):210-4.

40 WHO. The top 10 causes of death. 2020. Available from: https://www.who.int/newsroom/fact-sheets/detail/the-top-10-causesof-death.

41 Tanne JH. Covid-19: US cases are greatly underestimated, seroprevalence studies suggest. BMJ. 2020;370:m2988.

42 Schwalbe N. We could be vastly overestimating the death rate for COVID-19. Here's why. 2020. Available from: https://www.weforum. org/agenda/2020/04/we-could-be-vastlyoverestimating-the-death-rate-for-covid19-heres-why/.

43 Benedetti F, Pachetti M, Marini B, Ippodrino R, Gallo RC, Ciccozzi M, et al. Inverse correlation between average monthly high temperatures and COVID-19-related death rates in different geographical areas. J Transl Med. 2020;18(1):251

44 TCT Project. About the data. 2021. Available from: https://covidtracking.com/about-data/.

45 Ritchie H, Ortiz-Ospina E, Beltekian D, Mathieu E, Hasell J, Macdonald B, et al. Coronavirus (COVID-19) hospitalizations. 2020
Available from: https://ourworldindata.org/ covid-hospitalizations.

46 UNAIDS. Global HIV \& AIDS statistics: 2020 fact sheet. 2021.

47 Roser M, Ritchie H. HIV/AIDS. 2019 [cited 2021 Feb 23]. Available from: https://ourworldindata.org/hiv-aids\#almost-1-millionpeople-die-from-hiv-aids-each-year-insome-countries-it-s-the-leading-cause-ofdeath.

48 Sumner A, Hoy C, Ortiz-Juarez E. Estimates of the impact of COVID-19 on global poverty. 2020.

49 United Nations University. COVID-19 fallout could push half a billion people into poverty in developing countries. 2020. Available from: https://unu.edu/media-relations/releases/covid-19-fallout-could-push-half-abillion-people-into-poverty-in-developingcountries.html.

50 WHO. Coronavirus disease (COVID-19): herd immunity, lockdowns and COVID-19. 2020. Available from: https://www.who.int/ news-room/q-a-detail/herd-immunity-lockdowns-and-covid-19?gclid=CjwKCAjwr56I BhAvEiwA1fuqGqq2lUcE0vEE3dCESgwSAiNT2Uaofebp8vQdVEcOLpLkg5vE8Z8VARoCFmUQAvD_BwE\#.

51 Achenbach J. Proposal to hasten herd immunity to the coronavirus grabs White House attention but appalls top scientists, The Washington Post. 2020. Available from: https:// www.washington post.com/health/covidherd-immunity/2020/10/10/3910251c-0a6011eb-859b-f9c27abe638d_story.html.

52 Aschwanden C. The false promise of herd immunity for COVID-19, nature. 2020. Available from: https://www.nature.com/articles/ d41586-020-02948-4.

53 Jung F, Krieger V, Hufert FT, Küpper JH. Herd immunity or suppression strategy to combat COVID-19. Clin Hemorheol Microcirc. 2020;75(1):13-7.

54 Ritchie H, Ortiz-Ospina E, Beltekian D, Mathieu E, Hasell J, Macdonald B, et al. Coronavirus (COVID-19) vaccinations. 2021. Available from: https://ourworldindata.org/covidvaccinations.

55 Ministry of Health. Privacy policy. Available from: https://vaxcert.moh.gov.kw/tc/terms conditions.html.

56 Fiore K. Physicians eyeing third dose of COVID vaccine: despite many unknowns, healthcare professionals want reassurance, especially with Delta threat, MedPage Today. 2021. Available from: https://www.medpagetoday.com/special-reports/exclusives/ 93884 ? vpass $=1$. 